\title{
Study on China's Food Safety Issues and Supervision Platform Based on Credit Management
}

\author{
Song Guangxing ${ }^{1}$, Tian Tian ${ }^{2}$ \\ ${ }^{1}$ School of Public Management, Yunnan University of Finance and Economics, China \\ E-mail: gxsong_yn@163.com \\ ${ }^{2}$ School of Business Administration, Yunnan University of Finance and Economics, China \\ (E-mail: sunxiangrikui@163.com)
}

\begin{abstract}
Food safety issue exists not only in developing countries, but also it is actually a global problem. At present, China's food safety is a serious issue and major fatal food safety incidents occurred occasionally. Based on empirical study, this paper analyzed food safety issues and their causes from government regulation perspective. Food safety is closely related with ineffective government regulation-- lacking of credit and coordination mechanisms. Therefore, this paper proposed some suggestions to solve those problems, such as establishing a credit management platform for food safety and strengthening government regulation synergy mechanism.
\end{abstract}

Keywords: Food Safety, Government Regulation, Causes and Countermeasures

\section{Introduction}

According to the investigation report of the World Health Organization, every year there are a large number of consumers facing different food safety risks. As China is during the process of transformation, the food safety issue is more complex and difficult. In the past few years, China's food safety incidents broke out frequently, which even caused the fear of the consumer for food consumption. Although China has successively taken a series of actions, such as food safety action, special renovation for food safety, and construction of food safety credit system etc, some problems of producing and selling fake goods and other illegal activities are still very common, and the phenomenon of lacking of credit is also very serious. Therefore, to strengthen food safety supervision is imperative. Food safety is related to the knowledge of biology, health and quarantine science, political science, economics, management science, sociology and psychology and other disciplines. Domestic and foreign scholars in this field have carried out extensive research from different angles.

Researches on the issues of food safety focus on the following areas: the concept of food safety, influencing factors of food safety and behaviors of main subjects related food safety. 


\subsection{Studies on the concept of food safety and influencing factors of food safety}

Studies on food safety issues initially focused on the quantity of food security. In 1974's World Food Conference held by the United Nations Organization (FAO), the concept of food security was defined as: in any case, all people have access to adequate foods necessary to maintain a healthy survival. In 1980s, oversea researches on food safety issues began to gradually transfer from the quantity security of food to its quality safety. In Food Safety Law of People's Republic of China issued in 2009, food safety refers that the food is non-toxic, harmless, and conforming to proper nutritive requirements, and does not cause any acute, sub-acute or chronic hazards to human health.

Studies on the factors influencing food safety abroad were started as early as the 1990s, while the domestic is started a bit late. Research focusing in this regard in developed and developing countries are different. Developed countries focused on the new technology, trade, terrorism. Taking genetically modified foods for example, Taylor (1997) pointed out that the scientific and technological progress made the further application of new materials and new technology in food production, which led to uncertainties of food safety. Kasterner.J, Pawsey.R (2002) pointed out the impact of foreign food, and Parker (2005) studied the impact of food bio-terrorism. In contrast, domestic scholars such as Kan Xuegui(2001), Zhou Jiehong(2004), Liu Ting(2009) studied the factors affecting food safety problems mainly from environmental pollution, source pollution of aquaculture, harmful food additives, and market and government failure.

\subsection{Studies on the behaviors of main subjects related food safety}

These researches include motivation and effectiveness of food safety of the suppliers, food consumption psychology and behavior, and government behavior of food safety.

Holleran, E., Bredahl, M.ZaibetL (1999) first proposed the motivation of enterprises to improve food safety was divided into two categories: one is internal motivation for increasing profits and reducing the production costs, the other is external motivation related to the transaction costs. After that, other scholars further noted that motivation of enterprise food safety in different countries differed a lot[8][9],[10], and established an effectiveness formula for food safety from the view of costs and benefits[11]. For management system of enterprise food safety, studies focused on the implementation of the Hazard Analysis and Critical Control Point (HACCP) or ISO series of quality management system. British scholars in this field are particularly significant, as many scholars (such as Ehiri, Zaibet \& Bredahl, and Henson and Northen,) did an exhaustive study on the cost - benefit of HACCP system. Domestic scholars' study on the HACCP system is about how to create a HACCP food safety management system, and the role of the system to ensure food safety in the enterprises. For example, Song Jieshu(2005) and Yu Haiyan (2005), respectively, research the HACCP of the traditional liquor production enterprises and process of chilled meat processing. Zhang Jumei (2007) analyzed the difficulties in three stages: prior to the implementation of the HACCP plan, the implementation process and after the implementation. 
Research on food consumption psychology and behavior included consumers' willingness to pay, purchasing power and buying behavior. Foreign scholars' studies gradually turned from the buying behavior impacted by the consumers' individual characteristics to consumers' trust of government, environmental awareness, and psychological factors on food choices. The representative scholars include Elaine (1999), Henson and North (2000), etc. The domestic are mainly concentrated on consumer behavior. Such as Wang Zhigang (2003) and Zhang Xiaoyong (2004), who took consumers from Tianjin as study subjects, and analyzed food safety concerns of individual, and the process and characteristics when consumer selected food. Zhou Yingheng, Ou Yang Xi-hui (2006) analyzed the safety factors influencing consumer choice, which include the production date and shelf life, using of preservatives and pigments and other additives, and whether origin manufacturers and distributors getting the certification from relevant state agencies. There are also scholars (e.g. Ren Yan, Tang Xueyu, and Li Shiping) studied consumers' low degree of cognitive level on green foods, and analyzed main factors affecting consumers cognitive level, such as consumers' gender, educational level, occupational characteristics, and level of confidence on green foods.

Researches on government food safety behavior include the necessity for government regulation of food safety and the mechanisms of government's food safety control. The necessity of government regulation of food safety is grouped into two categories: a class regarded that government control is the game between various stakeholders to produce a balanced result from the game and equilibrium perspective [11], [12]; Based on the view that government is the agent of public interests, the other regarded government regulation as a necessary means to compensate for market failure as for market externalities and asymmetric information problem [13]. Domestic scholars like Zhou Deiyi, Xie Min, Yu Yongda ,etc(2002) proposed the necessity of strengthening government control of food safety, because market failure appears if the market simply relies on the market mechanism. Li Gongkui, Ying Ruiyao (2004) pointed out that primary cause of the "lemons problem" in the market was that there were defects in government regulation of food safety, while the solution to resolve the problem was reducing information asymmetry on food safety.

For mechanisms of government regulation on food safety, domestic and foreign scholars have done a lot of researches. Oversea scholars include Henson(1999), Loader R. and Hobbs J.E(1999). From their researches we can see that the main regulatory manners of food safety include establishing and promulgating laws, regulations and executive orders, issuing relevant food production licenses, rewarding and punishing the relevant acts, and implementing HACCP system, etc. Domestic scholars Yang Tianhe (2004), Zhao Lindu (2005), Zuo Jingsheng (2005) and Cheng Yanqing (2006) discuss the government food safety control behavior based on macroscopic angle, and put forward relevant policy suggestions, such as strengthening the legal laws and regulations, establishing the food safety control department, perfecting the relevant food standards, promoting consumer food safety cognition, and constructing the authentication and product recall systems. 


\section{China's food safety issues and their causes}

\subsection{China's food safety issues}

With the rapid development of China's market economy, the consumption trends of the society changes from focusing on the improvement of living standards to quality of life, and food safety has become a widespread concern, while the exposed food safety issues sounded the alarm of the people again and again. So many food safety issues are serious, which must be governed immediately. Taking the "Fuyang, Anhui Big Head" major food safety incident in 2004 as a starting point, food safety incidents exposed by the media present rising trend year by year. A large number of "black workshops" profiteer from selling fake goods, and even some well-known enterprises pursue their own interests at the expense of public interests, such as "Sudanhong event", "Red Duck egg event", "gutter cooking oil incident", "the Sanlu milk powder incident" and "poisonous bean sprouts", "tainted pork" and "leather milk" and other major food safety incidents. These food safety incidents often lead to social panic, seriously damaged public health and public safety. These food safety incidents are only the tip of the iceberg of the food safety issues, which show a growing trend. First of all, the unqualified foods involve more and more fields, from the traditional main by-product such as the original grain oil, meat, eggs, vegetables and soy products to dairy products, fruits, roasted seeds and nuts. Secondly, the harm degree of unqualified foods is increasingly deep from the surface health hazards to the internal safety hazards. Food inspection in the past only paid attention to the total number of food bacteria, while now it checks into residues of pesticides, fertilizers, chemicals etc. Finally, the production methods of fake and shoddy foods are more and more diverse and subtle, from the externality to the internality of food, and including both physical and chemical methods.

\subsection{Causes of food safety issues}

To some extent, above-mentioned phenomena are related to inadequate supervision of government, although there are still some other factors. Issues on government regulation are mainly in the following areas: regulatory laws and regulations and technical standards are imperfect, government regulation pattern is defective, government regulatory systems are unsound and corresponding inspection methods are backward, regulatory information is poor, and regulatory funding is inadequate.

China has basically formed the legal framework for food safety, for example, Food Safety Law, as the Basic Law, was supplemented by related regulations, local laws and regulations, and judicial interpretations, and is compatible with other laws. However, these laws and regulations do not cover all aspects of food safety, only include some more important aspects, and lack of integrity. Moreover, there are problems related to low legal effect and light punishment in our food safety law and regulation. In the case of no major food safety incidents, the penalties for violations of food safety often take a simple fine or suspend business for rectification, which unable to meet the pedagogical effect. Meanwhile, with the economic development and technological progress, a growing number of food additives and new technologies are applied to food production, but relevant laws, regulations and technical standards for construction are not updated timely, which could easily lead to 
confusion in management and potential safety hazard.

The state and local government are responsible for China's food safety supervision, while Central Government are composed of the Ministry of Health, Ministry of Agriculture, the State General Administration of Quality Supervision and the Ministry of Commerce, who are responsible for reporting to the State Council. These departments are self-contained, respectively, setting up corresponding extension agencies at the provincial, city and county level. These food safety regulatory agencies are directly responsible for the local government, and accept the management and technical guidance of the central agency. Each department forms a vertical system from the central to local, but central and local food safety regulators have not formed a unified and coordinated control system, and the relationship of food safety regulatory has not been straightened out. In this regulatory system, we take multi-sectoral segment regulatory approach, Ministry of Health, Ministry of Agriculture, the State General Administration of Quality Supervision and the Ministry of Commerce respectively supervise one section of food links. On the surface, all departments segmented supervision seems that there are multiple protection mechanisms, but in fact the phenomenon of regulatory overlap and regulatory gaps is serious. In multi-sectoral segment supervision, as the scope of regulation and regulatory content expanding, and the laws, regulations of provisions tend to use more general, vague language to describe the functions of the various regulatory department, so that the division of functions of the various departments is not clear, and there is a certain flexibility and misunderstanding, which will lead a lot of problems in food safety supervision. For division of functions is fuzzy, each department may order to maximize their own interests, competing custody or shirking its regulatory responsibility, resulting in a range of issues such as waste of regulatory resources, poor regulatory effectiveness, and high regulatory cost .

Government regulation being reasonable, must have a complete set of food safety control system, which includes food market access system, food certification system, food safety risk monitoring and evaluation systems, food recall system, and food safety accountability system. But so far, China has not established a comprehensive food safety control system, and the corresponding food safety inspection means is relatively backward, which is reflected in the food safety inspection equipment and inspection technology. In the day-to-day supervision and inspection process, supervisory staff relying on experience, validity, shelf life, trademark packaging etc, make a rough judgment through verification, inquiry, observation, which reduce the accuracy of the check results, The current inspection equipment like pesticide residue is time-consuming and difficult to promote, while the drugs and toxic substances residue testing methods and equipment are more scarce. These problems seriously hinder smooth supervision of food safety, are not conducive to investigate violations, and leave a hidden danger to food safety. At the same time, information asymmetry makes consumers less knowledge about pesticide residues, microbial contamination, etc. We should also note that efficient government regulation establishes on the basis of adequate funding. If there is not enough funding to ensure food safety, the equipments are not 
updated, and supervisory techniques are remained undeveloped, food safety supervision work will be restricted seriously. While funding shortage is another prominent problem of China's food safety supervision, the investment in testing agencies, the education and training of food employees, food safety research, and safety supervision network in China is far below the level of developed countries, which is also an important reason for China's food safety problems.

Here we analyzed the reasons for China's food safety issues mainly from the perspective of the government, while supplier, one of the main part of the market, due to a weak awareness of credit, are often driven by short-term interests to take the bad behaviors. Consumers with poor information on food safety are very vulnerable, especially the majority of rural residents, urban migrant workers and groups of students, and they are the main victims. Therefore, the behaviors of providers and consumers are important influence factors of food safety issues.

\section{Food safety credit supervision platform}

Food safety problems occur frequently, reasons of which including the imperfectness of laws and regulations and supervisory system, inadequate punishment, inefficient enforcement. Actually, it implies the imbalance in the game of all stakeholders in food chain, lack of social credit, and other deep-seated factors. All these factors are intertwined and make food safety issues more prominent. If resolving food safety issues only from the laws and regulations, regulatory framework, and regulatory system, we can only do passive monitoring, and cannot prevent counterfeit and shoddy foodstuffs into circulation. The root cause of ineffective government regulation is that it does not start from the essential reason of food safety issues - lack of credit and lack of coordination mechanisms. Therefore, in order to resolve food safety issues fundamentally, we should not only improve the government's regulatory mechanisms, develop a sound government regulatory system, and increase the regulatory funding, etc., but also accelerate the construction of food safety credit supervision platform, and strengthen collaboration between government sectors.

\subsection{Government collaboration regulatory mechanism}

The so-called synergy is the process that restructuring various parts of the entirety in aspects of time, space and functional structure to complete a particular job and project. Synergy can produce a cooperative and coordinated ability, which has far greater effects than each part of the entirety. By synergy we can effectively solve the problems of information asymmetry and resource inefficiency, while these issues are just difficulties of government regulations. Therefore, the synergy mechanism can also play an important role in government regulations.

Government regulation is a systematic engineering. According to system theories, various functional departments in a system can be considered to be subsystems. As parts of the whole system, subsystems are in close contact, and their function will directly affect the effectiveness of the whole system. Various functional sectors of the government refer to different aspects of food safety regulation, and each department has its own function and 
unique role, so problem in any part will affect the entire food chain security. Thus, functions synergy is critical to government supervision, and regulatory authorities should cooperate and coordinate with each other.

The government regulation takes a segmented regulation mode in food safety, while the information of the food enterprises scatters in different sectors like Trade and Industry Bureau, Tax Bureau and Bureau of Quality Supervision, and there is no exchange and sharing mechanism of information between various functional sectors, so information resources are sealed in different databases. All kinds of information of food enterprises are interrelated, and only after obtaining complete information can we make decisions, so this mode will cause serious waste of information resources. The scattered and irregular information can be integrated through information synergy mechanism of government regulation. Firstly, this integration needs an information platform to complete the collection of food credit information, so as to achieve a barrier-free flow of information among different functions, and ultimately all sectors complete collaboration and information sharing through this platform.

Carrying out government regulation needs the support of various resources, such as talents, financial, material, information, etc. While the phenomenon of resources waste is brought about by functions overlapping and regulatory overlap, and resources shortage is caused by regulatory funding shortage, we require coordinating resources among different regulatory authorities, so that limited resources play the greatest roles for the goal of food safety.

\subsection{Contents of building food safety credit supervision platform}

To set food safety credit supervision platform, we should consider: constructing food enterprise credit evaluation index system, collecting credit information of food companies from industry and commerce, taxation, quality supervision, financial institutions and other departments, constructing food enterprise credit information database, evaluating the credit of the food enterprise in accordance with the basic standards of food safety credit, releasing credit information of food enterprises, and rewarding trustworthy enterprises and punishing discreditable enterprises.

3.2.1. Credit evaluation index system of food enterprise

The credit evaluation index system of food enterprises should be consistent with China's national conditions, and based on the characteristics of food enterprises, We should analyze and integrate various factors that affect food safety credit systematically, so as to analyze food safety behavior of enterprises, and determine the size of the risk. The index system evaluates an enterprise from internal and external aspects, which has three grades. The first grade assessment indicators mainly cover factors of enterprise interior and exterior. The second grade indicators supplement the first grade assessment indicators in food production, processing and circulation parts. The third grade indicators give a detailed description of each link. These indicators cannot cover all the details of various enterprises. Therefore, indicators in each level can be expanded correspondingly and the grade of the index system can also be increased so as to make the index system more 
scientific and targeted. In this paper, a food enterprise credit evaluation index system is offered as a reference, shown in table 1 , and other types of enterprises or individual evaluation can use similar index system.

\begin{tabular}{|c|c|c|}
\hline First Lever Indicator & Second Lever Indicator & Third Lever Indicator \\
\hline \multirow{10}{*}{ Internal Evaluation } & \multirow{3}{*}{ Source Links } & Raw Material Purchase \\
\hline & & Raw Material Acceptance \\
\hline & & Raw Material Storage \\
\hline & \multirow{4}{*}{$\begin{array}{l}\text { Production and Processing } \\
\text { Links }\end{array}$} & Production Environment \\
\hline & & Conservancy of Sanitation \\
\hline & & Production Facility \\
\hline & & Product Quality Testing \\
\hline & \multirow{3}{*}{ Intermediate Links } & Product Stock \\
\hline & & Product Marketing \\
\hline & & Product Recall \\
\hline \multirow{5}{*}{ External Evaluation } & \multirow{3}{*}{$\begin{array}{c}\text { Regulatory Compliance } \\
\text { Information }\end{array}$} & Enterprise Qualification \\
\hline & & System Certification \\
\hline & & Operation \\
\hline & \multirow{2}{*}{$\begin{array}{c}\text { Social Assessment } \\
\text { Information }\end{array}$} & Trade Independent Management \\
\hline & & Consumer Evaluation \\
\hline
\end{tabular}

Table 1: Credit Evaluation Index System of Food Enterprise

The credit evaluation index system of food safety is a multi-layer and multi-index composite system, and the degree of importance of each indicator is different. We can adopt expert scoring method, AHP, principal component analysis, or entropy method etc. to determine the weight of each index. Based on credit evaluation criteria for food enterprises, we can get the evaluation of each indicator of a food enterprise, and then synthesize all indicators to get comprehensive credit score of it. Food enterprises credit score can be used as an important reference for the decision-making of consumers and other information users.

3.2.2. Collection of food enterprise credit information

Enterprise credit information collection is an activity of collecting, classifying, sorting, storing scattered enterprise credit information in society actors to form enterprise credit information database. When select the 
channels of food enterprise credit information, we should not only ensure the availability of information, but also consider the quality of information and acquisition costs. Food enterprise credit information comes from the executive institution (including the Consumers' Association), the judiciary institution, public institutions (including water, electricity, gas), financial institutions (mainly the People's Bank of China), social intermediary organizations (such as accounting affairs, professional credit reference agencies, etc.), industry associations, and the enterprise itself.

By the business sector we can get access to information of business registration, the credibility of the business-related activities, and corporate administrative penalty information etc. Food and Drug Administration can offer information of qualification approval, the enterprise authentication, and corporate illegal irregularities, while the inspection information of food production, processing, storage and other aspects comes from the Quality and Technical Supervision Authority and the Health Bureau. Other relevant enterprise credit information, such as corporate reputation, fulfillment of corporate social responsibility, assessment of the public, consumer complaints, etc., comes from other relevant agencies, such as consumer associations, social intermediary agencies, and trade associations, etc. At the same time, the news media reports can be used as an important source of credit information. The credit supervision platform collect information scattered in various departments and various departments can access to business information through the platform too, so as to achieve the information synergy of government regulation.
3.2.3. Using of food enterprise credit information

Credit supervision platform establishes contacts with various government regulatory authorities, government extranet, public networks, and enterprise networks, so credit data among different sectors and agencies transmit smoothly, and various functional sectors and agencies obtain expected data and services through the platform interface. Through the platform, sectors of government can inquire the information of the food enterprises, and take different forms of supervision based on the credit status of the enterprise. Meanwhile, various sectors coordinate and cooperate to improve the timeliness and effectiveness of the regulatory. The public can get query, complaints, and evaluation via the platform, so consumers can not only obtain comprehensive information on food safety, but also provide a reference for potential customers. Enterprises can use this platform as a good publicity platform and build corporate reputation and brand. If a company's credit rating is high, it will attract many consumers to buy its products or services, and finally, establish a corporate brand image. By checking the reputation of other companies on the platform, enterprises will improve the sense of competition. By viewing the complaints of consumer, a enterprise can increase the awareness of social responsibility. By viewing the latest information issued by the State, enterprises can understand the policies, regulations and industry trends and movements timely. The using of food enterprise credit information was shown in Fig. 1. 


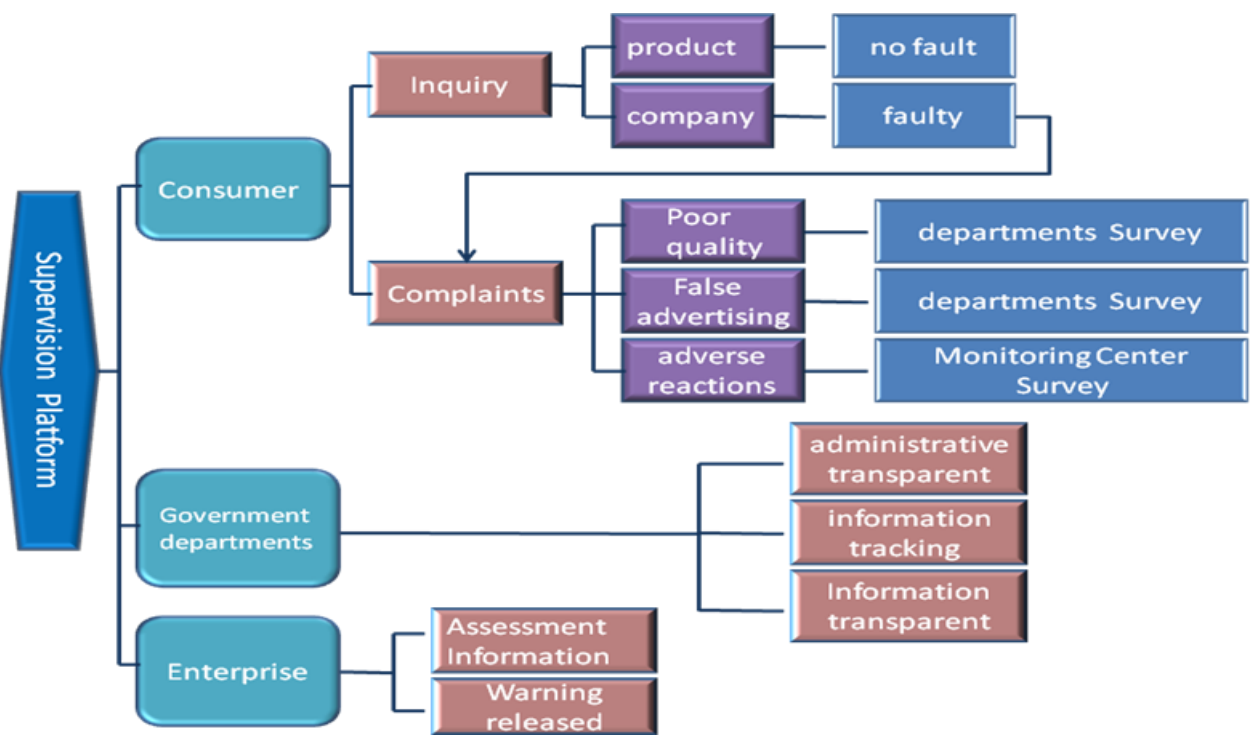

Fig. 1 Using of Food Enterprise Credit Information

In summary, food safety credit supervision platform can enhance communication, and promote coordination and cooperation among various functional sectors. So it can effectively reduce the phenomenon of regulatory overlap, regulatory gaps and resource waste in the regulatory process, improve regulatory efficiency and the processing speed of emergency, and achieve function and resource synergies of government regulation to some extent. At the same time, through releasing the credit information of enterprises, discreditable companies will be difficult to survive in the market, so as to achieve the purpose of fundamental solution to food safety issues.

\section{Conclusions}

Credit supervision platform of food safety, supervisory system and supervisory institution interact mutually. Therefore, building the credit supervision platform, strengthening awareness of food safety supervision, establishing relevant laws and regulations, developing safety standards, and restructuring supervisory system and supervisory institution, all above issues should also be considered.

First of all, the ideal of food safety supervisory should be transformed. The government should realize that the food safety is a dynamic organic process, so the supervision cannot be isolated. The ideal of integrated management through the whole food chain "from farmland to table" should be emphasized, so as to make full and effective monitoring, foreseeing and prevent the risk of food safety.

Secondly, the government should establish complete laws and regulations system and technology standards, which cover the whole process of food producing, processing and circulating. Meanwhile, the government should increase the investment for introducing or developing advanced supervisory equipments and technologies, improving the monitoring conditions, and providing strong activities to food safety guarantee.

Thirdly, we should learn from developed country, to build food call-back institution, food certification system and system of 
rewards and penalties, and to perfect the existing supervisory system.

\section{Acknowledgement}

This research was supported by the National Natural Science Foundation of China under Grant 70572068

\section{References}

[1] Taylor M R. Preparing America's food safety system for the twenty-first century-who is responsible for what when it comes to meeting the food safety challenges of the consumer-driven global economy?[J]. Food and drug law journal, 1997: 13-30.

[2] Kasterner, J., \& Pawsey, R.. Harmonizing sanitary measures and resolving trade disputes through the WTO-SPS framework. Part I: a case study of the US-EU hormone-traded beef dispute[J]. Food control, 2002,13 (1): 49-55

[3] Zheng Fengtian, Zhao Yang. China Agricultural Product Quality Safety Problems and Solutions[J]. China Software Science, 2003 (2):16 -20. (In Chinese)

[4] Kan Xuegui. China's accession to the WTO: health supervision and law enforcement agencies should be done[J]. Chinese Journal of Preventive Medicine. 2001 (1): 22-24. (In Chinese)

[5] Zhou Jiehong, Qian Fengyan, Ma Chengwu. food safety management issues and progress[J]. Agricultural Economics, 2004 (4): 26-39. (In Chinese)

[6] Liu Ting. Public food safety issues and government initiatives[J]. Journal of Inner Mongolia Agricultural University(Social Science Edition), 2009,11(3): 245-246.(In Chinese)
[7] Holleran, E., Bredahl, M. Zaibet L.. Private incentives for adopting food safety and quality assurance[J]. Food policy, 24 (1999): 669-683.

[8] Hobbs, J. E., Fearne, A., Spriggs, J. Incentive structures for food safety and quality assurance: an international comparison[J]. Food Control, 13 (2002): 77-81.

[9] Gomez, M I, Cabal, M P, Torres, J A. Private initiatives on food safety: the case of the Colombian poultry industry[J]. Food Control, 13(2002): 83- 86.

[10] Reardon, M. etc., Global Change in Agrifood Grades and Standards: Agribusiness Strategic Responses in Developing Countries[J]. International Food and Agribusiness Management Review, 2005: 421-435.

[11] Caswell, J., Bredahl, M., Hooker, N.. How quality management systems are affecting the food industry[J]. Rev. Agric. Econ. 20(1998): 547-557.

[12] Henson, S., Holt, G. Morthen, J. Costs and benefits of implementing HACCP in the UK dairy processing sector[J]. Food Control, 10(1999): 99-106.

[13] Arrow, K.J. et al. Benefits-cost analysis in environmental health and safety regulation: a statement of principles[J]. Washington D.C., The AEI Press. 1996.

[14] Ehiri, J. E., Morris, G. P., McEwen, J. Implementation of HACCP in food businesses: the way ahead[J]. Food Control,,1995, 6 (6): 341-345.

[15] Holleran, E., Bredahl, M. Transaction costs and institutional innovation in the British food sector[J]. Food Safety, 1997(3): 403-419.

[16] YU Haiyan, Luo Yongkang, Xiao Yang, Ye Weihua. The HACCP system 
establishing of pig slaughtering[J]. Meat Research, 2005 (6): 36 -38.(In Chinese)

[17] Song Jieshu. Liquor brewing companies how to implement the HACCP food safety management system[J], 2005, 33 (4): 76-78.(In Chinese)

[18] Zhang Jumei, Wu Qingping, Wu Huiqing,

Guowei Peng Major obstacle of food enterprises in the implementation of HACCP[J]. Food Science and Technology 2007, 35 (10): 122-124.(In Chinese)

[19] Elaine H. A. Factors affecting food decisions make by individual consumers[J]. Food policy, 1999, 24: 287-294.

[20] Henson, S, J. and Northen, J. Consumer Assessment of the safety of beef at the point of purchase: A pan-European study. Journal of Agricultural Economics[J], 2000, 51: 90-105.

[21] Wang Zhigang. Food safety cognition and consumption decisions: empirical analysis of Tianjin individual consumers $[\mathrm{J}]$. China's rural economy, 2003 (4),-45. (In Chinese)

[22] Zhang Xiaoyong, Li Gang, Zhang Li. Chinese consumers concerns to food safety -the survey and analysis of consumers in Tianjin[J]. China's rural observation, 2004 (1): $14 \quad-20$. (In Chinese)

[23] Zhou Yingheng, etc. Food safety: consumer attitudes, purchase intention and the influence of the information-the investigation and analysis of the supermarket consumers in Nanjing[J]. China's rural economy. 2004, (11): 53-59. (In Chinese)

[24] OuYang XiHui, Dong Yadong, Zhou Xubao, Hao Jianjiang. Consumer authentication edible agricultural products to the cognitive level and purchasing behavior analysis: based on the Beijing consumer survey of empirical studies [J]. Agriculture quality standards, 2006, 2: $26-29$

[25] Ren Yan, An Yufa. Consumer confidence in food safety and its influencing factors one from the agricultural products of Beijing Wholesale market survey analysis[J]. Consumer economy, 2009 (4): 45-48.

[26] Henson S. Caswell J., Food safety regulation: an overview of contemporary issues[J]. Food Policy. 1999 (24): 589-603.

[27] Xie Min, Yu Yongda. Analysis of food safety issues in China [J]. Shanghai Economic Research, 2002,1: 39. (In Chinese)

[28] Li Gongkui, Ying Ruiyao. "Lemon market" and institutional arrangements an analytical framework on agricultural product quality safety and security [J].Agricultural Technology Economy, 2004 (3): 15 - 20. (In Chinese)

[29] Loader R. Hobbs J. E. Strategic responses to food safety legislation[J]. Food Policy, 1999(24): 685-706.

[30] Zhao Lindu. Food safety and risk management[M]. Beijing: Science Press, 2009. (In Chinese)

[31] Cheng Yanqing. Food safety issues and its governance system analysis [J] Productivity Research, 2006,1:52 -54. (In Chinese) 